\title{
Television Observation of the Artificial Auroral Streaks Produced by the ECHO-IV Electron Beam Experiment
}

\author{
T.J. Hallinan, ${ }^{*}$ H.C. Stenbaek-Nielsen*, and J.R. WinCKLeR ${ }^{* *}$ \\ *Geophysical Institute, University of Alaska, Alaska, U.S.A. \\ **School of Physics and Astronomy, University of Minnesota, \\ Minneapolis, Minnesota, U.S.A.
}

(Received October 17, 1977)

Marker pulses from the Echo-IV rocket-borne electron accelerator were intended to produce optically detectable auroral streaks in the atmosphere. The program included both downward and upward injected beams. The latter were injected at a pitch angle chosen to magnetically mirror above the atmosphere in the southern hemisphere and to precipitate into the atmosphere upon the return to the northern hemisphere. This is possible since the magnetic field strength over Alaska is weaker than in the conjugate region (STENBAEK-Nielsen, 1974).

Ten streaks produced by the downward-injected beams were observed with a low-light-level television system. The threshold power for detection was found to be near $1 \mathrm{~kW}$. Although several of the upward-injected beams exceeded this threshold (sometimes more than $2 \mathrm{~kW}$ ), no 'echo' streaks were optically observed.

A number of weaker pulses, not intended for optical detection, produced 'echoes' that were detected by particle counters on board the rocket. Comparisons between the signals from detectors viewing different azimuthal directions around the fieldaligned payload suggest that the return beams were confined to small diameters (WINCKLER, 1976). If the echoes from the higher-current marker pulses are also well confined, then the lack of TV observations of the echo streaks implies that the precipitated energy is less than half of the original energy of the beam. This could result from pitch-angle scattering such that either some of the electrons precipitate in the southern hemisphere or some mirror above the atmosphere in the northern hemisphere.

The altitudes and vertical extents of the streaks were measured by assuming that the streaks are aligned parallel to the earth's magnetic field. Within the measurement accuracy, the measured altitudes and vertical extents were consistent with calculated values. This confirms similar observations of other artificial auroras (DAvis et al., 1971) and is significant in view of recent observations indicating that the height-luminosity distributions of some natural auroras depart significantly from theoretical profiles (STENBAeK-Nielsen et al., 1977).

The diameters of the streaks were also measured and an instrumental correction determined from laboratory tests of the television system was applied. The corrected widths ranged from 34 to $182 \mathrm{~m}$. The wider streaks had a generally fuzzy appearance 
in the TV images and resulted from beams injected while the rocket was near apogee $(215 \mathrm{~km})$. Beams injected before and after rocket-apogee produced narrow welldefined streaks. The differences in width are significant and do not appear to result from any instrumental effect. The cause of the anomalous broadening is still unknown.

\section{REFERENCES}

Davis, T.N., T.J. Hallinan, G.D. Mead, J.M. Mead, M.C. Trichel, and W.N. Hess, Artificial auroras experiment: Ground-based optical observations, J. Geophys. Res., 76, 6082-6092, 1971.

Stenbaek-Nielsen, H.C., Indications of a longitudinal component in auroral phenomena, J. Geophys. Res., 79, 2521, 1974.

WiNCKLER, J.R., A summary of recent results under the 'Echo' program for the study of the magnetosphere by artificial electron beams, Cosmic Phys. Tech. Rept. 168, School of Physics and Astronomy, University of Minnesota, Minneapolis, Minnesota, September, 1976.

Stenbaek-Nielsen, H.C., T.J. Hallinan, and T.N. Davis, Stereo-TV observations of pulsating aurora, J. Geomag. Geoelectr., 30, 1978 (in press). 